\title{
Further observations on platelet aggregation induced by adenosine diphosphate thrombin and tri-ethyl tin
}

\author{
J. R. O'BRIEN
}

From the Portsmouth and Isle of Wight Pathological Service

sYNOPSIS Aggregation induced by adenosine diphosphate is inhibited by adenosine as well as by adenosine mono- and triphosphate. Thrombin-induced aggregation is also inhibited by adenosine and the monophosphate, but the triphosphate at a similar concentration is not inhibitory. Aggregation induced by tri-ethyl tin is accelerated by a critical concentration of triphosphate and delayed by a higher concentration. The tri-ethyl tin effect is inhibited by 5-hydroxytryptamine and by tryptamine. Platelets from patients treated with reserpine respond normally to these last two substances. Incubated platelets lose first their ability to respond normally to tri-ethyl tin, then to thrombin, and lastly to adenosine diphosphate. These results are briefly discussed.

A new and sensitive method of studying platelet aggregation, that is, the adhesion of one platelet to another, was recently reported (O'Brien, 1962) and it was suggested it might help towards a more detailed understanding of the problems of aggregation. Some further observations are reported here. Of particular interest is the finding that 5-hydroxytryptamine is shown to have an effect on platelet behaviour. Some possible implications of these findings will be discussed in another paper.

\section{METHOD}

As previously described, $2 \mathrm{ml}$. of pooled human citrated platelet-rich plasma containing about 400,000 platelets and 400 white cells per c.mm. was placed in a magnetically stirred cuvette at $37^{\circ} \mathrm{C}$. in a colorimeter. The optical density was recorded at five-second intervals. If aggregation occurred the optical density decreased. If the clumped platelets came apart the optical density increased. Additions to give the final concentrations reported were added in $0.1 \mathrm{ml}$. of barbitone-buffered saline.

\section{RESULTS}

ADENOSINE INHIBITION OF ADENOSINE DIPHOSPHATEINDUCED AGGREGATION Adenosine diphosphate, final concentration $5 \mathrm{M} \times 10^{-7}$, added to stirred platelet-rich plasma caused moderate aggregation and then disaggregation. The prior addition of

Received for publication 8 March 1963. adenosine $5 \mathrm{M} \times 10^{-6}$ prevented aggregation. If 10 times as much diphosphate was used the amount of adenosine needed to inhibit it also had to be increased. Adenosine mono- and triphosphate were inhibitory in the same manner and at the same strengths. On some occasions adenosine seemed to be fractionally more inhibitory than the phosphates. Table I and Fig. 1 summarize these and other results.

ADENOSINE AND ADENOSINE TRIPHOSPHATE AND THROMBIN-INDUCED AGGREGATION Thrombin added

\section{TABLE I}

INHIBITION OF AGGREGATION INDUCED BY ADENOSINE DIPHOSPHATE, THROMBIN, AND TRI-ETHYL TIN

\begin{tabular}{|c|c|c|c|}
\hline & $\begin{array}{l}\text { Adenosine } \\
\text { Diphosphate } \\
5 M \times 10^{-7}\end{array}$ & $\begin{array}{l}\text { Thrombin } \\
(0 \cdot 1 \mathrm{u} / \mathrm{ml} .)\end{array}$ & $\begin{array}{l}\text { Tri-ethyl Tin } \\
5 M \times 10^{-5}\end{array}$ \\
\hline Adenosine & $5 M \times 10^{-}$ & $5 \mathrm{M} \times 10^{-6}$ & $5 M \times 10^{-3}$ \\
\hline $\begin{array}{l}\text { Adenosine mono- } \\
\text { phosphate }\end{array}$ & $5 \mathrm{M} \times 10^{-6}$ & $5 M \times 10^{-6}$ & $5 \mathrm{M} \times 10^{-4}$ \\
\hline $\begin{array}{l}\text { Adenosine tri- } \\
\text { phosphate }\end{array}$ & $5 \mathrm{M} \times 10^{-6}$ & $\left\{\begin{array}{l}5 \mathrm{M} \times 10^{-6} \\
\text { No effect } \\
5 \mathrm{M} \times 10^{-2} \\
\text { Inhibits }\end{array}\right.$ & $\left\{\begin{array}{l}5 \mathrm{M} \times 10^{-6} \\
\text { Accelerates } \\
5 \mathrm{M} \times 10^{-3} \\
\text { Delays }\end{array}\right.$ \\
\hline $\begin{array}{l}\text { 5-Hydroxy- } \\
\text { tryptamine }\end{array}$ & No effect & No effect & $1.25 \mathrm{M} \times 10^{-3}$ \\
\hline Tryptamine & No effect & No effect & $1.25 \mathrm{M}$ \\
\hline
\end{tabular}

In the table are listed the concentrations of the inhibitors which inhibit aggregation induced by the compounds at the head of each column, except as otherwise stated. 

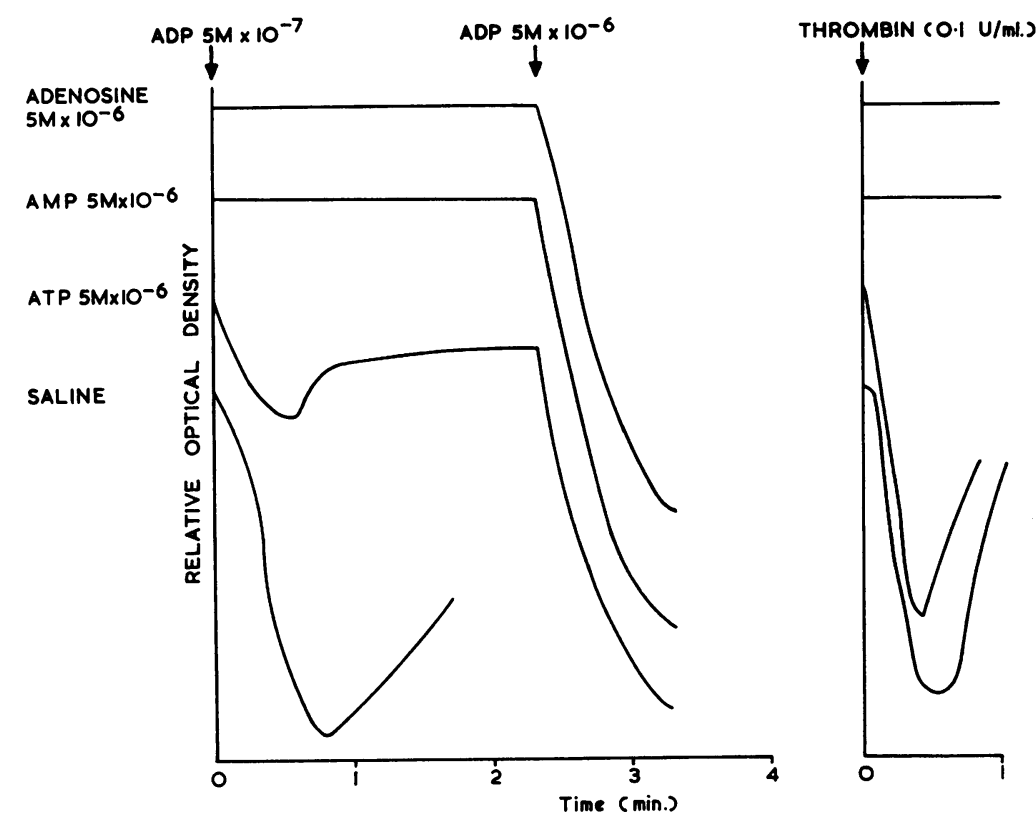

FIG. 1. Adenosine or adenosine monophosphate (AMP) or adenosine triphosphate $(A T P)$ in the strengths indicated or normal saline were added to stirred platelet-rich plasma $37^{\circ} \mathrm{C}$. Five minutes later adenosine diphosphate $(A D P)$ or thrombin were added $(\downarrow)$ in the strength indicated. In the diphosphate experiments a further addition of tenfold stronger diphosphate was added three minutes later.

to stirred platelet-rich plasma to give a final concentration of $0 \cdot 1 \mathrm{u} / \mathrm{ml}$. caused moderate aggregation then some disaggregation and then clotting. The prior addition of adenosine, $5 \mathrm{M} \times 10^{-6}$, inhibited aggregation and so did adenosine monophosphate at the same concentration. The triphosphate had no inhibitory effect until the strength was increased to $5 \mathrm{M} \times 10^{-3}$.

ADENOSINE DIPHOSPHATE AND TRIPHOSPHATE AND TRI-ETHYL TIN-INDUCED AGGREGATION Tri-ethyl, $5 \mathrm{M} \times 10^{-5}$, added to stirred platelet-rich plasma induced rapid aggregation after a delay of three to 10 minutes depending on the plasma used ( $O$ 'Brien, 1963). The addition of adenosine triphosphate, $5 \mathrm{M} \times 10^{-6}$, five minutes before adding the tri-ethyl tin caused a marked shortening of the delay which then lasted only two to five minutes. Adenosine triphosphate, $5 \mathrm{M} \times 10^{-3}$, prolonged the delay to longer than the original time. A lower concentration of adenosine, $5 \mathrm{M} \times 10^{-5}$, or monophosphate, $5 \mathrm{M} \times 10^{-4}$, caused complete inhibition of the triethyl tin effect. It will be noted that adenosine again appears to be a slightly more efficient inhibitor than the monophosphate. The addition of adenosine diphosphate, $M \times 10^{-6}$, at the same time as the tri-ethyl tin produced its own normal response which was immediately followed by further aggregation due to the tri-ethyl tin. If tri-ethyl tin was added one minute after the adenosine diphosphate when disaggregation had begun the delay period was markedly shortened. If the tri-ethyl tin was added 11 minutes after the diphosphate the delay was as long as if no diphosphate had been added (Fig. 2).

TRYPTAMINE AND 5-HYDROXYTRYPTAMINE EFFECT OF $\stackrel{\circ}{\stackrel{D}{2}}$ TRI-ETHYL TIN-INDUCED AGGREGATION The addition $\overrightarrow{\overrightarrow{0}}$ of 5-hydroxytryptamine creatinine sulpahte or trypt- $\exists$ amine hydrochloride, $5 \mathrm{M} \times 10^{-4}, 10$ minutes before tri-ethyl tin sometimes completely inhibited aggre-음 gation. 5-Hydroxytryptamine, $1 \cdot 25 \mathrm{M} \times 10^{-3}$, usually prevented tin-induced aggregation. On occasions? when 5-hydroxytryptamine was ineffective at the 3

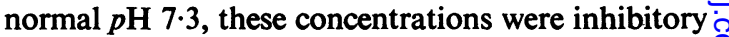
if the $p \mathrm{H}$ of the platelet-rich plasma was adjusted to 8.0 by the addition of sufficient sodium hydroxide. This change of $p \mathrm{H}$ had no effect on aggregation induced by tri-ethyl tin alone. If the concentration $\frac{D}{O}$ of tri-ethyl tin was increased or decreased within the narrow effective range $M \times 10^{-4}$ to $2 \mathrm{M} \times 10^{-6}$ the $N$ strength of 5-hydroxytryptamine needed to inhibit $N$ the reaction also had to be increased $\left(1 \cdot 25 \mathrm{M} \times 10^{-3}\right)$ N or decreased $\left(5 \times \mathrm{M}^{-4}\right)$ in parallel. Creatinine sul- $\omega$ phate at the same concentration was not inhibitory? and neither tryptamine nor 5-hydroxytryptamine at these concentrations inhibited thrombin and adenosine diphosphate-induced aggregation.

EFFECT OF RESERPINE AND RO 3-0837 ON TRI-ETHYL $\stackrel{\vec{\oplus}}{\mathrm{D}}$ TIN-INDUCED AGGREGATION Six patients were shown $\stackrel{\circ}{\odot}$ to respond normally to tri-ethyl tin and this response was inhibited by 5 -hydroxytryptamine. The patients 


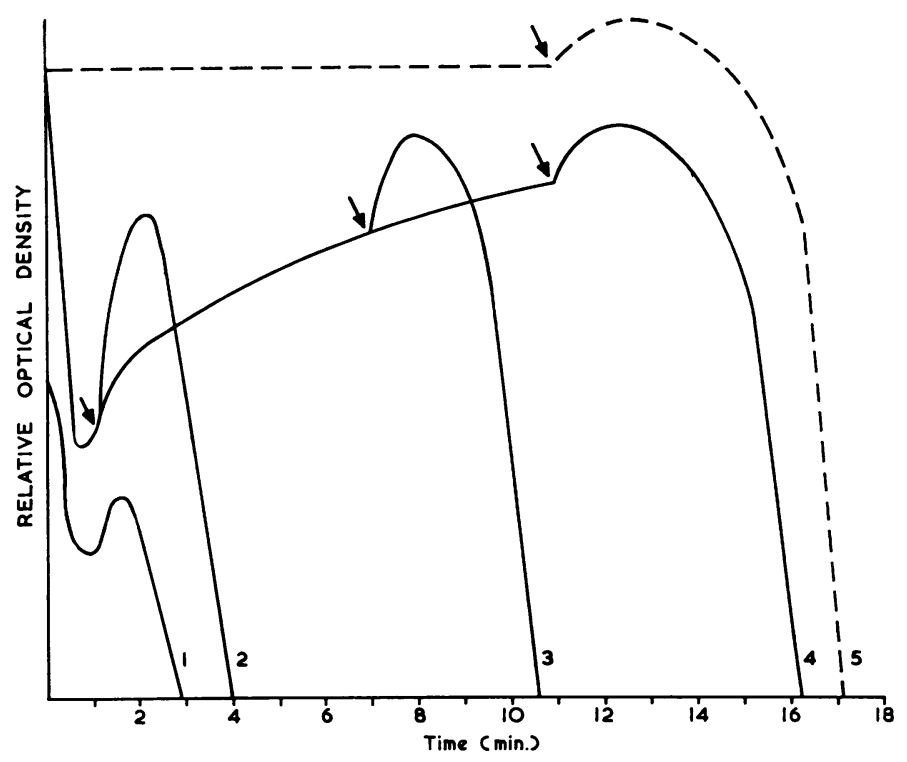

FIG. 2. Adenosine diphosphate $M \times 10^{-6}$ was added at zero time in curves $1,2,3$, and 4 . In curve 1 tri-ethyl tin $5 M \times 10^{-5}$ was also added at zero time: in curves 2,3 , and 4 its addition is indicated thus $\downarrow$. In curve 5 saline was added at zero time and the tri-ethyl tin addition is indicated $(\downarrow)$.

were then given reserpine, $0.75 \mathrm{mg}$. a day, and seven and 14 days later the tests were repeated. No difference was detected. Pre-incubation of plateletrich plasma with Ro 3-0837 $5 \mathrm{M} \times 10^{-5}$, another powerful mono-amino oxidase inhibitor, did not alter the inhibitory effect of 5-hydroxytryptamine on tri-ethyl tin-induced aggregation.

TEMPORAL DECAY OF RESPONSE TO ADENOSINE DIPHOSPHATE, THROMBIN, AND TRI-ETHYL TIN Sterile platelet-rich plasma was kept either at $37^{\circ} \mathrm{C}$. or at $22^{\circ} \mathrm{C}$. on the bench. At suitable intervals adenosine diphosphate or thrombin or tri-ethyl tin was added to aliquots of this platelet-rich plasma and any aggregation on stirring was noted. At room temperature on average the normal response to triethyl tin failed after one day, the response to thrombin failed after two days, and the response to adenosine diphosphate after three or four days. The failure to aggregate in response to these different compounds occurred faster at $37^{\circ} \mathrm{C}$. and varied a little with different batches of plasma, but the sequence was always the same.

\section{DISCUSSION}

Some more general conclusions will be discussed in a separate communication. The finding that adenosine inhibits the adenosine diphosphate effect in the same competitive way and at the same concentrations as adenosine monophosphate and adenosine triphosphate supports the suggestion that these materials fit into a 'slot' by virtue of their adenosine moiety and that only when two phosphate groups are present can 'stickiness' be produced.

A number of workers, for example Grette (1962), have shown that thrombin causes intrinsic adenosine triphosphate in platelets to change in minutes to adenosine diphosphate, and thus presumably aggregation induced by thrombin is due to the formation and liberation of intrinsic adenosine diphosphate. The effect of adding adenosine triphosphate is therefore of theoretical importance. At a suitable concentration it might constitute an increase in the available substrate and thus speed up or increase the response to thrombin. No such effect was found but the result of adding triphosphate was nevertheless anomalous. Monophosphate, $5 \mathrm{M} \times 10^{-6}$, or adenosine, $5 \mathrm{M} \times 10^{-6}$, were inhibitory. Triphosphate at this strength is as inhibitory as adenosine or the monophosphate when aggregation is induced by diphosphate, but permits full thrombin-induced aggregation; presumably it had been converted into diphosphate. The high concentration of triphosphate $\left(5 \mathrm{M} \times 10^{-3}\right)$ needed to inhibit thrombin-induced aggregation is presumably effective because the great excess successfully competes with the diphosphate formed.

The observation that a critical concentration of adenosine triphosphate accelerates the aggregation caused by tri-ethyl tin is compatible with the suggestion that tri-ethyl tin stimulates an adenosine triphosphatase in platelets (O'Brien, 1963), particularly since tri-ethyl tin is known to stimulate mitochondrial adenosine triphosphatase (Aldridge, 
1958). As in the case of thrombin-induced aggregation excess triphosphate might be expected to compete with the diphosphate formed and delay (or inhibit) aggregation, as was in fact observed.

Small quantities of adenosine diphosphate added with or immediately before tri-ethyl tin virtually eliminates the long and curious delay before triethyl tin normally causes aggregation. At present no explanation is offered.

It is of great interest that 5-hydroxytryptamine and tryptamine inhibit the effect of tri-ethyl tin, and 5-hydroxytryptamine is more effective in an alkaline medium. 5-Hydroxytryptamine is extensively distributed in the body and has many well-studied pharmacological effects but no record has been found (apart possibly from the following reports) of it being involved in a system that must involve one or at most a few enzymes. Born, Ingram, and Stacey (1958) found that the amount of 5-hydroxytryptamine normally taken up by platelets depended on the concentration of adenosine triphosphate in the platelets. Sano, Kakimoto, and Taniguchi (1958) found that added adenosine triphosphate increased uptake of 5-hydroxytryptamine. Accordingly, it seems that uptake of 5-hydroxytryptamine may in some circumstances depend on a metabolic pathway involving adenosine triphosphate. Thus, if it is accepted that tri-ethyl tin stimulates an ATPase, the metabolism of each compound may affect the metabolism of the other. In reserpinized platelets the adenosine triphosphate level is normal but these platelets cannot take up 5-hydroxytryptamine. The present observation that reserpinized platelets behave normally with 5-hydroxytryptamine and tri-ethyl tin is therefore anomalous.

Platelets increasingly damaged by ageing lose their ability to respond to diphosphate after they have lost their ability to respond to thrombin and tri-ethyl tin. This is a necessary finding if it is true that triethyl tin and thrombin cause aggregation by liberating or making available intrinsic adenosine diphosphate.

My thanks are due to the Wessex Regional Hospital Board for a research grant. Adenosine and adenosine mono-, di-, and triphosphate were supplied by Sigma Chemical Co., Dr. W. H. Aldridge kindly gave me the N tri-ethyl tin, and Dr. J. Marks of Roche Products the $\omega$ 5-hydroxytryptamine creatinine sulphate. My especial 9 thanks are due to Miss J. Patrick for technical assistance.

\section{REFERENCES}

Aldridge, W. H. (1958). Biochem. J., 69, 367.

Born, G. V. R., Ingram, G. I. C., and Stacey, R. S. (1958). Brit. J. Pharmacol., 13, 62.

Grette, K. (1962). Acta physiol. scand., 56, suppl., 195.

O'Brien, J. R. (1962). J. clin. Path., 15, 446.

(1963). Thrombos. Diathes. haemorrh. (Stuttg.), in press.

Sano, I., Kakimoto, Y., and Taniguchi, K. (1958). Amer. J. Physiol., $195,495$. 